\title{
Assessment of Land Surface Models in a High Resolution Atmospheric model during Indian Summer Monsoon
}

\author{
Raju Attada*1, Prashant Kumar ${ }^{2}$ and Hari Prasad Dasari ${ }^{1}$
}

1. Physical Sciences and Engineering Division, King Abdullah University of Science and Technology (KAUST), Thuwal, Saudi Arabia

2. Atmospheric and Oceanic Sciences Group, Space Applications Centre, Ahmedabad380015, India

\section{Revision Submitted to Pure and Applied Geophysics}

Corresponding author's address:

Raju Attada

King Abdullah University of Science and Technology (KAUST),

Physical Sciences and Engineering Division,

Thuwal, Saudi Arabia

Email: rajuattada@gmail.com 


\begin{abstract}
Assessment of the land surface models (LSMs) on monsoon studies over the Indian summer monsoon (ISM) region is essential. In this study, we evaluate the skill of LSMs at $10 \mathrm{~km}$ spatial resolution in simulating the 2010 monsoon season. The thermal diffusion scheme (TDS), rapid update cycle (RUC), Noah and Noah with multi-parameterization (Noah-MP) LSMs are chosen based on nature of complexity, that is, from simple slab model to multi-parameterization options coupled with the Weather Research and Forecasting (WRF) model. Model results are compared with the available in situ observations and reanalysis fields. The sensitivity of monsoon elements, surface characteristics and vertical structures to different LSMs are discussed. Our results reveal that the monsoon features are reproduced by WRF model with all LSMs, but with some regional discrepancies. The model simulations with selected LSMs is able to reproduce the broad rainfall patterns, orography induced rainfall over the Himalayan region, and dry zone over the southern tip of India. The unrealistic precipitation pattern over the equatorial western Indian Ocean is simulated by WRF-LSM based experiments. The spatial and temporal distributions of top 2-meter soil characteristics (soil temperature and soil moisture) are well represented in RUC and Noah-MP LSM based experiments during the ISM. Results show that the WRF simulations with RUC, Noah and Noah-MP LSM based experiments significantly improved the skill of 2-meter temperature and moisture compared to TDS (chosen as a base) LSM based experiments. Further, the simulations with Noah, RUC and Noah-MP LSMs exhibit minimum error in thermodynamics fields. In case of surface wind speed, TDS LSM performed better compared to other LSM experiments. Significant improvement is noticeable in simulating rainfall by WRF model with Noah, RUC and NoahMP LSMs over TDS LSM. Thus, this study emphasis the importance of choosing/improving LSMs for simulating the ISM phenomena in a regional model.
\end{abstract}


Key words: Indian summer monsoon, High resolution model, Land surface models, Error analysis

\section{Introduction}

Indian Summer Monsoon (ISM) is one of the spectacular features of the global atmospheric general circulation and is an important potential tipping element of the climate system (Krishnan et al. 2003). India receives more than $80 \%$ of the annual rainfall during summer monsoon months (e.g. Webster et al. 1998; Rajeevan et al. 2013) and reliable monsoon prediction is highly challenging task due to its nature of complexity (Webster et al. 1998; Prasanna 2014). It is recognized that the interactions between land, ocean and atmosphere strongly influence the ISM (e.g. Levermann et al. 2009; Boos and Kuang, 2013). Moreover, a strong and rapid heating (cooling) of the land in the seasonal cycle has a large impact on atmospheric differential heating (cooling) between land and ocean. The changes in land surface fields modulate the surface fluxes, temperature, circulation and precipitation patterns (Levermann et al. 2009; Unnikrishnan et al. 2013). Asharaf et al. (2012) demonstrated that land surface process affects the ISM in a complex way due to the interactions between land and atmosphere.

Previous studies confirmed that the land and atmosphere interactions have been identified as one of the important sources of monsoon variability (e.g. Shukla and Mintz 1982; Webster 1983; Meehl 1997; Ferranti et al. 1999; Koster et al. 2004; Takata et al. 2009; Saha et al. 2012). It is also worth mentioning that the land surface is a slowly varying forcing of the ISM. Due to lack of land surface observations, it restricts the ability to demonstrate the impact of land surface on the monsoon rainfall. Therefore, it is essential to understand and improve the physical processes associated ISM using high resolution regional models. 
In recent years, regional models have been adopted for a wide variety of applications including weather and climate forecasting (e.g. Liang et al. 2012; Wang et al. 2004). The dynamical downscaled regional models significantly improved the representation of ISM due to the advantage of spatial resolution and more accurate representation of different physical process (Giorgi et al. 2001; Wang and Yang 2008; Hari Prasad et al. 2011; Liang et al. 2012; Srinivas et al. 2013; 2015; Raju et al. 2014, 2015a). In regional models, the land surface parameterization (LSM) plays an important role as it controls the surface fluxes of momentum, heat and moisture between the surface and atmosphere (Betts et al. 1996; Pielke 2001; Srinivas et al. 2014).

The performance of the model highly depends on the representation of different physical processes and is mainly from LSMs through the representation of land-atmosphere interactions (Viterbo and Beljaars 1995; Liang et al. 2005; Yuan and Liang 2011, Xu et al. 2014). Different LSMs use different approaches to describe the complex land surface processes in the regional models and are important to study the effect of different LSMs on seasonal scale simulations. Though the recent developments in LSMs significantly improved the model performance, it is still a challenging task to improve the accuracy of land surface processes (Cai et al. 2014). Recently, Srinivas et al. (2014) reported that the physical processes of landsurface energy influence the regional behavior of the monsoon system at regional scale. Kar et al. (2014) used the Weather Research and Forecasting (WRF) model to examine the importance of vegetation green fraction in the context of the regional hydroclimate over the India with onemonth simulations. Singh et al. (2007) studied the influence of LSM on the ISM circulation characteristics for the month of July and suggested the importance of LSMs. Clearly, these studies suggest that land surface process has a significant impact on the ISM. It is important to consider that the high resolution regional models are beneficial in resolving the regional 
processes in more accurate and detail. Earlier studies are mostly configured with coarse resolutions, and the length of the simulations are limited.

In this study, we used four different LSMs in the WRF model for the simulation of the ISM-2010, about four months at a high resolution of $10 \mathrm{~km}$. Among these four schemes, the TDS scheme is the simplest, the Noah-MP is complex, and the Noah and RUC schemes are at an intermediate level of complexity. Hence, the primary goal of the present study is to evaluate the performance of WRF model with different LSMs (from simple LSM to multi-physical LSM) in simulating the ISM-2010 features. The ISM-2010 is a normal monsoon year with the seasonal rainfall of $102 \%$ of its long-term average (Raju et al. 2014). It is also influenced by different regional and global features and is also witnessed with an intense La Niña (Pai and Sreejith 2011; Mujumdar et al. 2012).

The paper is organized as follows. Section 2 presents the model, the experimental design and the details of LSMs. Section 3 examines the ability of the model in reproducing the mean monsoon features. Error analysis for LSM is provided in section 4, and the summary and conclusions are presented in section 5 .

\subsection{Model, Experimental Design and Methodology}

\subsection{Model details and Experimental Design}

The regional model, WRF model version 3.4.1 (Skamarock et al. 2008) employed in this study is a limited area, non-hydrostatic primitive equation model with various physical parameterization schemes. The physics options used in this study consist of the Purdue Lin (Chen and Sun 2002) scheme for microphysics, Betts-Miller-Janjic (Janjic 1994) scheme for the convective parameterization, the Rapid Radiative Transfer Model (Mlawer et al. 1997) for longwave radiation, Dudhia scheme (Dudhia 1989) for shortwave radiation, the MoninObukhov (Monin and Obukhov 1954) similarity scheme for surface layer, and the Yonsei University planetary boundary layer scheme for boundary layer (Noh et al. 2003). The land 
surface processes are resolved by using different LSMs. The main characteristics of various LSMs are summarized in Table 1 . The model domain extends between $40^{\circ} \mathrm{E}$ to $130^{\circ} \mathrm{E}$ zonally and $30^{\circ} \mathrm{S}$ to $40^{\circ} \mathrm{N}$ meridionally with $10 \mathrm{~km}$ grid spacing. The vertical grid consists of 40 full sigma levels, more densely spaced within the planetary boundary layer. The lowest sigma level set to near the surface (top layer of $1 \mathrm{~cm}$ ) and the top of the atmosphere is prescribed at $50 \mathrm{hPa}$. The model has been integrated for about five months starting from 1 May to 30 September. National Centers for Environmental Prediction (NCEP) final analysis data (FNL) on $1^{\circ} \times 1^{\circ}$ spatial resolution is used for the initial and boundary conditions. Six-hourly interval meteorological data including wind, temperature, water vapor, pressure, and land surface state variables from the NCEP FNL data are used to generate the initial and lateral boundary conditions. The time varying sea surface temperature, monthly vegetation fraction, monthly land surface albedo and Leaf Area Index (LAI) data are used as low boundary conditions. The simulation corresponding to June to September (JJAS) is used for analysis allowing the first month (i.e. May) as a spin up time. One month spin up time is sufficient to obtain the dynamical equilibrium between the lateral forcing and the internal dynamics of the model (Anthes et al. 1989). It also removes spurious effects of the top layer soil moisture adjustment. The daily real time global sea surface temperature (Thiebaux et al. 2003) is used as the slow varying lower boundary condition in the model. Topography, snow cover and the land surface properties such as albedo and vegetation fraction are obtained from United States Geological Survey (USGS) available at spatial resolution 30".

\subsection{Data used}

The European Center for Medium-Range Weather Forecasts (ECMWF) Interim reanalysis (ERAI) data available (Simmons et al. 2007) at a spectral resolution of T255, which is approximately $0.75^{\circ} \times 0.75^{\circ}$ resolution, is used to compare the model simulated fields. ERAI 
data is considered for validation as it is an independent data source for model validation. The design of experiments is in such a way that NCEP analyses are used for initial and lateral boundary conditions, and ERAI data are used to validate model predictions. The daily precipitation from the model is compared with the daily gridded rainfall data of India Meteorological Department (IMD) available at $0.25^{\circ} \times 0.25^{\circ}$ resolution (Rajeevan et al. 2006) for the land areas, and the Tropical Rainfall Measuring Mission (TRMM) 3B42 data at $0.25^{\circ} \times 0.25^{\circ}$ resolution for the land and oceanic regions (Huffman et al. 2007).

\subsection{Description of Land Surface Models}

The WRF model provides a choice of different LSMs differing in the number of prognostic variables, accounted processes and complexity of their representation. This study uses four different LSMs that are described here.

The Thermal Diffusion Scheme (TDS) uses the force-restore method to solve the thermal diffusion equation to estimate the soil temperature at five soil layers of $1,2,4,8$, and $16 \mathrm{~cm}$ (Dudhia 1996). It does not predict the soil moisture and computes the relative amount of latent heat flux based on the available moisture that depends on land use category, which is constant in time and no explicit vegetation processes involved in the model. Further, the model does not consider the dynamics of soil moisture and it does not contain a snow scheme.

The Rapid Update Cycle (RUC) scheme solves the heat diffusion and Richards's moisture transfer equations at six or more levels (Smirnova et al. 1997, 2000, 2016). The RUC model is largely focused on accurate characterization of the soil up to 6-9 soil levels reaching down to a soil depth of $300 \mathrm{~cm}$. The physics of snow and phase change in soil are well characterized in RUC (Smirnova et al. 1997, 2000). Soil moisture coefficients are specified as functions of 11 textural classes of soil plus peat presented in Clapp and Hornberger (1978). Soil classification used in RUC is STATSGO classification with 16 categories. Energy and moisture budgets are solved in a thin layer spanning the ground surface and including half of 
the top soil layer and half of the first atmospheric layer, with corresponding heat capacities and densities. Vegetation impact on evaporation is taken into account with canopy moisture being a prognostic variable and evapotranspiration parameters depending on the vegetation type (e.g. McCumber, 1980; Smirnova et al. 1997). The model uses a basic approach to characterize evapotranspiration from the canopy (e.g. Pan and Mahrt, 1987). In our experiments, six vertical levels are considered and albedo, greenness and LAI specified based on USGS. We also specify landuse parameters based on a mosaic approach (i.e. mosaic_soil $=1$ and mosaic_lu $=1$ ).

The Noah LSM is a 1-D column model that can be applied in coupled or uncoupled mode. In the Noah LSM, soil temperature and soil moisture are predicted in 4 layers of 10, 30, 60 , and $100 \mathrm{~cm}$ (from top to bottom) based on canopy moisture and water-equivalent snow depth (Chen and Dudhia, 2001). The Noah LSM has one canopy layer, and its total depth of soil layers is 2-meter $(\mathrm{m})$. The upper $1 \mathrm{~m}$ of soil serves as the root zone depth, and the lower $1 \mathrm{~m}$ of soil serves as a reservoir with the gravity drainage. The surface skin temperature is calculated based on a single linearized surface energy balance equation that represents the surface vegetation. Soil temperature is estimated by solving the thermal diffusion equation, and the Richards equation is used to estimate the soil moisture. The vegetation impact on evaporation is taken into account similar to RUC, but canopy resistance is parameterized in terms of four environmental stress functions. Vegetation classification, using monthly estimates of albedo and fraction of green vegetation cover, is based on 16 land cover classes of the SSiB model (Loveland et al. 1995; Dorman and Sellers, 1989). The soil texture is determined from the 16-category soil dataset (Miller and White. 1998). Evapotranspiration is modelled by the Ball-Berry equation by taking both the physics of water flow through the soil and plants as well as the physiology of photosynthesis into account.

Multi-parameterizations are available within the Noah model (referred as Noah-MP) to improve the model in order to maximize complexity for dominant processes, while using 
simpler modeling approaches for other processes in order to conserve computational requirements (Ek et al. 2003; Niu et al. 2011). Noah-MP includes the response of transpiration to the changes in site water via soil moisture and variations of the response of conductance to soil matric potential. Site hydrology can be modelled as in Noah with the leaky bottom either with the simplified calculations of surface runoff or with more complex calculation of surface runoff based on the Biosphere-Atmosphere Transfer Scheme (Yang et al. 1995). Alternatively, the TOPMODEL-based (Niu et al. 2005) calculation of surface runoff and groundwater discharge is available with varying levels of complexity in modeling groundwater. Noah-MP has adopted new model processes developed over the past decade or so, including interactive vegetation canopy, groundwater, and multilayer snow. As opposed to prescribed LAI from observations, interactive vegetation canopy means that LAI is a prognostic variable that responds to the variability of precipitation, temperature, radiation, and availability of nutrients (Dickinson et al. 1998; Thornton et al. 2007). Although, introducing this type of dynamic leaf models may sometimes degrade model performance (Rosero et al. 2009, 2010), this approach adds vegetation as a memory process to the land system for seasonal climate forecasts (Jiang et al. 2009). Moreover, Noah-MP (Niu et al. 2011) divides the snowpack into three and five layers respectively, depending on total snow depth. Such multilayer snowpack physics could potentially improve the accumulation and melt of snow, and thus improve the timing of runoff generation. The inclusion of these processes has improved the model's performance in simulating moisture (Cai et al. 2014). The various options of these scheme used in this study are given in Table 2. In the subsequent sections, the performance of all LSMs are studied by analyzing various variables such as temperature, pressure, wind components, water vapour, soil moisture and soil temperature and rainfall including diagnostic variables like tropospheric temperature, moist static energy and precipitable water. 


\section{Results and Discussions}

\subsection{Mean State}

In this section, the mean ISM features from WRF model with different LSMs are assessed during ISM-2010. Figure 1 shows the spatial distribution of mean sea level pressure and tropospheric temperature during monsoon season. ERAI (Fig. 1a) shows the heat low extending from Pakistan to eastern Myanmar, the offshore trough over the west coast of India and a steep surface pressure gradient between the northern India and the southern Indian Ocean. The WRF model with selected LSMs is able to simulate the surface heat low and meridional pressure gradients as seen in ERAI. However, model simulations with Noah and Noah-MP LSMs produced higher spatial correlation coefficients (SCC) $0.98,0.98$ respectively than TDS $(\mathrm{SCC}=0.96)$ and $\mathrm{RUC}(\mathrm{SCC}=0.97)$ based experiments. The spatial distribution of tropospheric temperature (TT; averaged between 700-400 hPa) from ERAI and WRF model exhibit the meridional gradient in TT (i.e. higher temperature over the Tibetan region and lower temperature over the southern Indian ocean). The WRF experiments with Noah, RUC and Noah-MP LSMs show higher temperature $(\sim 270 \mathrm{~K})$ over Tibetan plateau. It has been widely accepted that the Tibetan plateau provides an elevated heating source to the middle troposphere, and therefore, the land-atmosphere interactions play an important role in formation of the ISM (Yanai et al. 1992; Yanai and Wu 2006; Xu et al. 2010). The differential heating between the ocean and land over the Indian subcontinent is a major factor in the creation of the monsoon circulations. Therefore, the mean lower (at $850 \mathrm{hPa}$ ) tropospheric monsoon circulation from ERAI and model are presented in Figure 2. The major circulation features (Fig. 2a) include the lower tropospheric monsoon circulation, low level jet (Somali jet) over Arabian Sea (AS) and easterly winds at the south of the equator are well captured in the WRF model with all LSMs (Fig. 1b-e) but with strong westerlies compared to ERAI. The core of low level jet is stronger and extended towards the Indian land region in RUC and Noah- 
MP LSM based model experiments. The strong winds in RUC and Noah-MP LSMs based experiments are may be due to the stronger tropospheric temperature gradient (TTG) between land and ocean. RUC based experiment shows highest mean TTG (2.7) followed by Noah-MP (2.5), Noah (2.2) and TDS (2.0) based experiments. Overall, the low level monsoon circulation is better represented in the Noah based experiments compared to other selected LSMs.

Moist Static Energy (MSE) in the lower troposphere $(1000-600 \mathrm{hPa})$ is a good indicator for convective instability during the ISM (Srinivasan and Smith, 1996). Maximum values of MSE over the central, northern and eastern ISM season are seen in ERAI (Fig. 3a). The WRF model with different LSMs are able to simulate the distribution of MSE over the Indian subcontinent but with considerable differences. The model experiments with TDS LSM (Fig. 3b) show the displacement of maximum MSE zone towards the west compared to ERAI and also it failed to simulate higher values over north-eastern region. In case of Noah LSM (Fig. 3c), maximum MSE (high unstable) region is in good agreement with ERAI but its extension towards the north-eastern region is limited. The WRF model with RUC (Fig. 3d) and NoahMP (Fig. 3e) LSMs display a better spatial distribution of MSE compared to that of ERAI. We also computed vertically integrated precipitable water (PW) from model simulations and ERAI. It is observed that the maximum values of PW (about $60 \mathrm{~kg} \mathrm{~m}^{-2}$ ) are located over the land region (MCR and north-eastern India) along with adjacent oceanic regions. The higher values of PW lead the higher values of MSE at the surface and lower troposphere, indicating the unstable air to form convective ascent and rainfall (e.g. Sabin et al. 2013). Overall, the characteristics of MSE and PW are simulated reasonably well from the WRF model with all selected LSMs with a slight underestimation over the equatorial Indian Ocean.

Figure 4 shows the spatial distribution of monsoon seasonal rainfall from TRMM (satellite observations) and model simulations. TRMM (Fig. 4a) shows the maximum rainfall over the west coast of India, north-eastern India, eastern equatorial Indian Ocean and foot hills 
of Himalayas, and minimum rainfall over north-west India and southeast peninsular India. WRF model with all LSMs is able to produce the maximum and minimum rainfall regions during ISM-2010 and are in well agreement with observations. However, model overestimated the rainfall patterns over the Bay of Bengal $(\mathrm{BoB})$ and adjacent regions. Interestingly, WRF model with all these LSMs are captured the finer details of orographic driven precipitation along the foothills of the Himalayas as in the observations. Moreover, all WRF-LSMs produce the unrealistic Inter Tropical Convergence Zone (ITCZ) type of precipitation pattern in the equatorial western Indian ocean region. It is evident that this unrealistic ITCZ is not sensitive to LSMs and it might be due to the model inherent problem (Raju et al. 2015a, b). Overall, the WRF model with selected LSMs are produced seasonal mean features of ISM and it needed further analysis before making any conclusion on the importance of LSMs.

\subsection{Spatial and Temporal distribution of soil temperature and soil moisture}

\subsubsection{Spatial distribution}

The spatial distribution of soil temperature and soil moisture at top $2 \mathrm{~m}$ soil column during the monsoon season from observations and model simulations are presented in Figure 5. It is important to emphasize that the vertical structure of soil layers is distinct in different LSMs. In this work, we consider top $2 \mathrm{~m}$ soil column that obtained by linear interpolation of LSM layers among them for one-to-one comparison. ERAI (Fig. 5a) shows maximum soil temperature (>305 K) over the north-west India and Pakistan, where the monsoon heat low is located, and also over Indo-Gangetic plain and southern tip of India. Minimum soil temperature values $(<300 \mathrm{~K})$ are observed over the west coast, north-eastern India and central India. The soil temperature distribution is simulated by WRF model with these LSMs but considerable differences are noticed. The WRF simulation with the Noah (Fig. 5b) LSM exhibits overestimation of soil temperatures over north-western region, whereas RUC (Fig. 5c) and 
Noah-MP (Fig. 5d) based experiments display the realistic distribution of soil temperature compared to ERAI.

Soil moisture, is the water stored in the upper soil layer, is a crucial parameter for a large number of applications including flood forecasting, agricultural drought assessment and, water resources management. Spatial distribution of soil moisture from model and observations illustrated in Figure 5(e-h). Maximum soil moisture $\left(0.3-0.4 \mathrm{~m}^{3} \mathrm{~m}^{-3}\right)$ is observed over the southwest coast of India, monsoon core region (MCR) and north-eastern parts of India, where high rainfall occurs during monsoon. Low soil moisture (less than $0.2 \mathrm{~m}^{3} \mathrm{~m}^{-3}$ ) is observed over the southeast India and north-west India, where less rainfall occurs. All LSMs experiments with WRF model are simulated the soil moisture distribution comparable to the ERAI. Noah, RUC and Noah-MP based WRF model simulations show higher values of soil moisture along the foothills of the Himalayas, north-eastern regions of India and MCR. However, WRF with RUC LSM is slightly reduced over the foothills of Himalayas, but it is in good agreement with Noah-MP based experiment over the MCR. Our results are well agreeing with the high resolution land surface derived data for the ISM by Unnikrishnan et al. (2013). WRF experiments with RUC and Noah-MP LSMs perform better in representing soil moisture due to their subsurface soil interactions.

\subsubsection{Temporal distribution}

Soil temperature and moisture are considered the slowly varying boundary conditions and so has a longer period of feedback to the atmosphere. Figure 6a shows the temporal evolution of top $2 \mathrm{~m}$ soil column of soil temperature averaged over the MCR during ISM-2010. ERAI shows a higher soil temperature (about 305K) during initial phase of monsoon and a gradual decrease with the monsoon progression (reached to $302 \mathrm{~K}$ ). Except TDS LSM, remaining all simulations with LSMs show the maximum soil temperature at the initial phase of the monsoon and also 
daily variation of soil temperature (decreasing trend). Most of the season, WRF with RUC LSM is close to the ERAI soil temperature evolution, whereas WRF with Noah LSM is well matched in phase changes over MCR compared to ERAI. It is also noted that model simulations with Noah-MP, RUC and TDS underestimated the soil temperatures at top $2 \mathrm{~m}$ layer during entire monsoon season. Similar results are noticed in bottom soil layers (Figure not displayed), but the WRF with RUC LSM is performing relatively better in simulating soil temperature over the MCR.

Figure 6(b) depicts the temporal evolution of top $2 \mathrm{~m}$ soil column of soil moisture averaged over the MCR during ISM-2010. The soil moisture from ERAI shows less value (0.2 $\mathrm{m}^{3} \mathrm{~m}^{-3}$ ) at initial stage of the monsoon, and it gradually increased with the monsoon progression as monsoon rainfall contributes the soil wetness. Here, we showed the soil moisture from Noah, RUC and Noah-MP based experiments only, since TDS based experiment cannot provide soil moisture information. WRF model with selected LSMs display less soil moisture $\left(0.3 \mathrm{~m}^{3} \mathrm{~m}^{-3}\right)$ during initial stage of monsoon (where less rainfall occurs) and then gradually increases $(0.4$ $\mathrm{m}^{3} \mathrm{~m}^{-3}$ ) with the monsoon progression but with the higher rate of increase compared to ERAI. Overestimation of soil moisture in the model with these LSMs may be due to the moist bias in the WRF dynamics, and also the choice of microphysics and convection schemes. Therefore, analysis indicate that the proper representation of soil moisture and soil temperature is great challenge in in WRF-LSMs model. The inaccurate representation of the surface soil characteristics over the MCR may cause improper surface energy budget estimation in different LSMs (e.g. Asharaf et al. 2012).

\section{Error analysis}

To quantify the model skill, we have computed different statistical measures (described below) between the different LSM based WRF simulations and ERAI. The spatial distribution of errors 
is time average value for each grid point, and temporal errors are an average value for all grid points. The rainfall forecast is compared with the IMD gridded rainfall. An improvement parameter (IP; Eq. 1) in $\mathrm{mm}^{-1 a y^{-1}}$ is used to quantify the improvements in the model with different LSM based experiments. Forecast impact (FI; Eq. 2) is also computed for different LSMs based experiments (e.g. Raju et al. 2015c). It gives the percentage improvement in predicted parameter with respect to CNT.

$$
\begin{gathered}
\mathrm{IP}=\delta=\sqrt{\frac{1}{N} \sum_{i=1}^{N}\left(C N T_{i}-O B S_{i}\right)^{2}}-\sqrt{\frac{1}{N} \sum_{i=1}^{N}\left(E X P_{i}-O B S_{i}\right)^{2}} \\
F I=\frac{\sqrt{\frac{1}{N} \sum_{i=1}^{N}\left(C N T_{i}-O B S_{i}\right)^{2}}-\sqrt{\frac{1}{N} \sum_{i=1}^{N}\left(E X P_{i}-O B S_{i}\right)^{2}}}{\sqrt{\frac{1}{N} \sum_{i=1}^{N}\left(C N T_{i}-O B S_{i}\right)^{2}}} \times 100 \\
\operatorname{RMSD}(\mathrm{CNT})=\sqrt{\frac{1}{N} \sum_{i=1}^{N}\left(C N T_{i}-O B S_{i}\right)^{2}} \\
\operatorname{BIAS}(\mathrm{CNT})=\frac{1}{N} \sum_{i=1}^{N}\left(C N T_{i}-O B S_{i}\right)
\end{gathered}
$$

Where "CNT" is the forecast when TDS LSM (as it is simplest LSM) is used for ISM prediction, and "EXP" is the forecast when RUC, Noah and Noah-MP LSMs are used for prediction, and "OBS" is the ERAI analysis or IMD rainfall, $\mathrm{N}$ is the total number of gridpoints. A positive (negative) value of IP/FI provides improvement (degradation) in the model prediction compared to TDS LSM (CNT) experiments. Student's t-test, which is provided below, has been applied to identify the most statistical significant zones at $95 \%$ confidence level.

$$
t=\frac{\bar{x}-\bar{y}}{\sqrt{\frac{s_{1}^{2}}{n_{1}}+\frac{s_{2}^{2}}{n_{2}}}}
$$


It is applied on number of days (during JJAS). Here " $x$ " is referred as "TDS" LSM based run and " $y$ " is referred as other LSM like Noah, RUC and Noah-MP based runs. Here, $\bar{x}$ and $\bar{y}$ are mean of $x$ and $y, s_{i}^{2}$ are unbiased estimator of the variance of each of the two samples with $n_{i}$ equal to number of participants in group i $(i=1$ or 2$)$.

\subsection{Temperature}

Spatial distribution of RMSD in $2 \mathrm{~m}$ air temperature from the experiment with TDS LSM against ERAI shows minimum (less than $2{ }^{\circ} \mathrm{C}$ ) error over the oceanic regions (Fig. 7) and maximum RMSD is found over land regions mainly over the northern India, Pakistan, Afghanistan, Tibetan plateau region, Saudi Arabia, Iran and Iraq. It is also noted that the highest RMSD $\left(7-10^{\circ} \mathrm{C}\right)$ is found over the Iran and Saudi Arabia compared to other regions. A cold (warm) BIAS is noticed over land (oceanic) region in TDS LSM experiment compared to ERAI (Figure not shown) and is larger than $5{ }^{\circ} \mathrm{C}$ over the Iran and Saudi Arabia regions. Similar patterns of cold BIAS are also seen in WRF runs with Noah and Noah-MP LSM, whereas WRF with RUC LSM represents less BIAS over these regions. RUC and Noah LSM based experiments show warm BIAS over the northern India region, and BIAS is less in Noah-MP LSM based experiment. Spatial distribution of IP (Fig. 7b-7d) shows that the RUC, Noah and Noah-MP LSMs based WRF model experiments improve the $2 \mathrm{~m}$ air temperature prediction compared to model simulation with the TDS LSM. The maximum (more than 2 to $5{ }^{\circ} \mathrm{C}$ ) improvement in temperature is found over the Iran and Saudi Arabia regions when RUC LSM is used in the place of TDS LSM in the model. The largest improvement in RUC LSM based experiment over this region among the LSMs might be related to precise estimation of surface fluxes that depends on the accuracy of the soil temperature/moisture profiles. Significant improvements are also observed over the Indian and Tibetan plateau regions. The 
accountability of high vertical resolution of soil layers may also be the reason for these improvements in WRF simulation with RUC LSM. Noah and Noah-MP LSM based experiments also show similar improvement in temperature against TDS based experiment. Domain average value of FI is $\sim 38 \%, 31 \%$ and $27 \%$ for Noah, RUC, Noah and Noah-MP based experiments respectively. The improvement of these LSMs over TDS advocate the importance of soil moisture, which lacks in TDS LSM.

Figure 8 displays the temporal distribution of BIAS and RMSD in $2 \mathrm{~m}$ air temperature during ISM-2010. Figure represents that Noah $\left(-0.02{ }^{\circ} \mathrm{C}\right)$ and Noah-MP LSM $\left(-0.36{ }^{\circ} \mathrm{C}\right)$ based experiments have less BIAS compared to TDS and RUC LSM based experiments (Fig. 8a). It is interesting to note that $\operatorname{TDS}\left(-0.87^{\circ} \mathrm{C}\right)$ and $\operatorname{RUC} \operatorname{LSM}\left(0.39^{\circ} \mathrm{C}\right)$ based WRF runs show the BIAS in temperature is opposite in nature i.e. TDS (RUC) LSM based experiment represents cold (warm) BIAS. It is also observed that the mean temperature forecasts show that the WRF with RUC (TDS) underestimate (overestimate) surface temperature against ERAI. Domain average value of RMSD (Fig. 8b) of $2 \mathrm{~m}$ temperature shows that the WRF with TDS LSM has a maximum error in predicting the $2 \mathrm{~m}$ temperature as compared to other three LSMs during monsoon season. Noah and Noah-MP LSMs based experiments are slightly better than TDS LSM based model simulation, however, Noah based model simulation is slightly better than Noah-MP. On the other hand, $2 \mathrm{~m}$ temperature prediction in RUC LSM based model simulation is improved after June, that may be due to the sub-surface layer processes, and its feedback to the atmosphere compared to other LSMs based experiments. Overall, it is also noted that the time mean of RMSD of $2 \mathrm{~m}$ temperature in RUC $\left(2.11^{\circ} \mathrm{C}\right)$ based model simulation is less than the TDS $\left(3.04{ }^{\circ} \mathrm{C}\right)$, Noah $\left(2.3{ }^{\circ} \mathrm{C}\right)$ and Noah-MP $\left(2.44{ }^{\circ} \mathrm{C}\right)$ based model simulations during ISM-2010.

An accurate representation of land surface physics not only improves the near surface representations but also modifies the upper level meteorological parameters through the land- 
atmospheric feedbacks. To verify this, the BIAS and RMSD for vertical profile of temperature are shown in Figure 9. The minimum value of BIAS is found (Fig. 9a) in TDS LSM based model simulation at low levels (1000-850 hPa), and all selected LSM based model simulations produced similar nature of BIAS and RMSD. The maximum error in boundary layer is noted from RUC LSM based model run, and slightly more BIAS is found in Noah-MP based experiment compared to Noah LSM based experiment. At mid-levels (800-550 hPa), Noah based model simulation shows the minimum BIAS compared to other LSMs based experiments. Vertical profile of domain average RMSD from different LSMs based model simulation shows (Fig. 9b) that RMSD is minimum in Noah and RUC LSMs based model simulation at surface whereas, TDS and NoahMP based model simulations show maximum. However, WRF runs with Noah and Noah-MP LSM perform better in entire troposphere than TDS and RUC LSM based model run for temperature during ISM-2010. It is important to mention that all LSMs based model simulations show the minimum errors in the middle troposphere. Though, the land surface processes are strongly coupled with different layers of the atmosphere, monsoon induced diabatic heating process may be playing important role in the middle troposphere.

In general, monsoon system is manifested by low and upper level circulation. Analyzing meteorological variables at upper level $(200 \mathrm{hPa})$ is equally important in model. Figure $10 \mathrm{a}$ is the spatial distribution of RMSD for upper level $(200 \mathrm{hPa})$ temperature in WRF run with TDS LSM. Maximum RMSD over the northern India particularly over the Tibetan plateau and minimum (less than $1.5^{\circ} \mathrm{C}$ ) over the land and oceanic regions is noticed. Spatial distribution of IP in RUC (Fig. 10b), Noah (Fig. 10c) and Noah-MP (Fig. 10d) over TDS LSM based model simulation shows a significant improvement over the Tibetan region indicates that LSM plays an important role on upper level temperature prediction. These large improvements in these LSMs based model runs are mainly because of the sub-surface soil moisture representation, which is not available in TDS LSM based model run. Approximately around $8 \%$ and $12 \%$ improvement 
in domain average value of FI is found in RUC and Noah based runs compared to TDS based model simulation. This improvement is significantly higher in Noah-MP LSM based model run where multi-parameterization play role in modulating upper level weather. The major improvements in the WRF model with Noah-MP LSM may be due to the better representation of sensible and latent heat fluxes over Tibetan regions, which help in better representation of the circulation and temperature in the upper troposphere.

\subsection{Water Vapor Mixing Ratio}

Spatial distribution of RMSD in 2m water vapour mixing ratio (WVMR) for TDS LSM based model simulation shows (Fig. 11) less error over the oceanic region and Indian landmass. More than 3 g. $\mathrm{Kg}^{-1}$ RMSD is found over the Saudi Arabia, Iran, Pakistan and southern Afghanistan

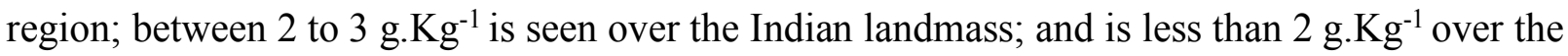
western Ghats (WG). The moisture prediction with RUC, Noah and Noah-MP LSMs based model simulations is improved significantly over the foothills of Himalayas, Tibet, China and Iran region. Slightly positive impact is found over the southern India in Noah and Noah-MP LSMs based model runs compared to TDS LSM based model run. However, the WRF model with Noah LSM degrades the forecast over the northern India region. This region shows very less to negligible improvement when Noah-MP LSM is used for ISM prediction in the WRF model. Similar kind of negative impact over the northern India is found in the WRF model with RUC LSM. The degradation of $2 \mathrm{~m}$ WVMR over this semi-arid region compared to TDS based model simulation is observed in these models. Domain average value of FI indicates that the RUC, Noah and Noah-MP LSM based model simulations significantly improved the WVMR prediction of $7.6 \%, 2.8 \%$ and $7.6 \%$ respectively compared to TDS LSM based model simulation. Spatial distribution of FI for upper level water vapour from all LSMs based model experiments (Figure not shown) display a significant improvement in RUC and Noah-MP based model simulations. 
Figure 12 shows daily BIAS and RMSD in $2 \mathrm{~m}$ dew point temperature prediction from different LSMs based model simulations during 01 June 2010 to 30 September 2010. Noah ($\left.0.49^{\circ} \mathrm{C}\right)$ and Noah-MP LSM $\left(-0.15^{\circ} \mathrm{C}\right)$ based experiments show less BIAS compared to TDS $\left(0.78^{\circ} \mathrm{C}\right)$ and RUC $\left(-0.87^{\circ} \mathrm{C}\right) \mathrm{LSM}$ based experiments. It is interesting to note that the dew point temperature shows reverse nature of BIAS compared to RUC and TDS LSMs based model simulations. Dew point temperature prediction displays positive (negative) BIAS in TDS (RUC) LSM based experiment. Initially for 01 June to 30 June, the minimum value of RMSD is found in TDS based model run and started increase RMSD throughout the period. Noah and RUC LSM based model simulations show higher RMSD compared to the experiment with Noah-MP LSM for dew point prediction. But after 15 August 2010, RMSD is more or less similar in RUC, Noah and Noah-MP LSM based model simulations. The large RMSD at initial stage of monsoon suggests that the one-month long spin-up period may not be sufficient for models to adjust in land surface processes. The time mean of RMSD is $3.44{ }^{\circ} \mathrm{C}, 3.37{ }^{\circ} \mathrm{C}, 3.34^{\circ} \mathrm{C}$, and $3.19{ }^{\circ} \mathrm{C}$ with the Noah, RUC, TDS and Noah-MP LSMs based model simulations respectively.

\subsection{Wind Speed}

Spatial distribution of RMSD of $10 \mathrm{~m}$ wind speed shows more than $2 \mathrm{~ms}^{-1}$ (Fig. 13a) over the study region and slightly higher wind speeds over the BoB compared to the AS. Large error is found over the Iran, southern Pakistan and Himalayan regions in TDS LSM based model simulation. Interestingly, the WRF model with TDS LSM shows high RMSD (3-5 ms ${ }^{-1}$ ) over the oceanic convective regions. Implementing of RUC, Noah and Noah-MP LSMs do not show much positive impact on the surface wind speed prediction. The domain average of FI is $-10 \%$, $-2 \%$ and $-4 \%$ for RUC, Noah and Noah-MP based model simulations respectively. Slightly positive impact is seen in RUC LSM based experiment, but over the oceanic region large degradation is found in this LSM compared to TDS LSM based model run. Marginal positive impact is found in Noah and Noah-MP LSM based model runs over the AS near the Oman, but 
more degradation is found in Noah-MP based model experiment compared to WRF model with Noah LSM.

Similar results are seen in the daily surface wind speed prediction, and it indicates that the wind speed prediction is better in TDS LSM based model run compared to other three LSM based experiments. All the LSMs based model simulations show positive BIAS in predicting 10m wind speeds during ISM-2010 (Fig. 14a). Higher BIAS is found in RUC based experiment $\left(0.97 \mathrm{~ms}^{-1}\right)$ compared to Noah-MP $\left(0.71 \mathrm{~ms}^{-1}\right)$, Noah $\left(0.63 \mathrm{~ms}^{-1}\right)$ and TDS $\left(0.52 \mathrm{~ms}^{-1}\right)$ based model runs. RMSD in wind speed forecast (Fig. 14b) shows that during June and July, the WRF model with RUC (TDS) LSM exhibits the maximum (minimum) error. RMSD is slightly less for Noah LSM based model run for the remaining period. The time mean of RMSD for wind speeds is $2.66 \mathrm{~ms}^{-1}, 2.52 \mathrm{~ms}^{-1}, 2.46 \mathrm{~ms}^{-1}$ and $2.42 \mathrm{~ms}^{-1}$ for RUC, Noah-MP, Noah and TDS LSMs based model simulations respectively. In case of upper level wind speeds (Figure not shown), TDS based model run has higher RMSD over entire domain. FI with respect to TDS based experiment shows a slight degradation over Tibetan region in RUC based model run.

\subsection{Rainfall}

Assessment of regional distribution of rainfall during monsoon is ultimate aim of any model. Our previous analysis from Figure 4, the high rainfall is observed over the WG, north-east India and Himalayan regions and less rainfall over the western India and rain-shadow region of peninsular India. All LSM based model experiments are able to reproduce the similar rainfall distribution during ISM-2010. The spatial distribution of daily average IMD gridded rainfall and WRF model with different LSMs predicted rainfall over the Indian landmass region (Figure not shown) are analyzed. Compared to IMD rainfall, TDS and RUC LSMs based model simulations overestimate the rainfall over the central India and are not able to capture the high rainfall over the orographic region of north-east and WG. Slight overestimation of rainfall is found over the 
WG region in RUC based experiment, whereas Noah LSM based model run could capture the rainfall over the central India compared to other two WRF-LSMs.

Figure 15 shows the spatial distribution of RMSD between the WRF model with TDS LSM and IMD gridded rainfall. Higher errors over the WG, north-eastern India and central India regions, and lower errors over the rain-shadow region in peninsular India and Rajasthan desert are noticed. Spatial distribution of IP in RUC, Noah and Noah-MP LSMs based model runs over TDS LSM based model run is presented in Figure 15 (b-d). It clearly indicates the implementation of RUC, Noah and Noah-MP LSM significantly improved the rainfall prediction compared to TDS LSM during ISM-2010. More than $5 \mathrm{~mm}$ of IP is found over the most of the Indian land regions, whereas few pockets of degradations are also seen over the WG, Gangetic plain and north-eastern part of India. Domain average value of FI is significantly higher $(6.8 \%)$ in Noah LSM based model simulation compared to other LSMs based experiments. The improvement in rainfall found over the India in RUC (3.7\%) and Noah-MP (3.6\%) based model simulations but slight improvement seen in RUC LSM experiment. A significant improvement in rainfall with Noah LSM based model simulation is due to the better representation of the surface characteristics and the vertical structures of thermodynamic variables. We also performed the regional statistics for $2 \mathrm{~m}$ air temperature, $2 \mathrm{~m}$ dew-point temperature and $10 \mathrm{~m}$ wind speed over the monsoon core region (i.e. $69^{\circ} \mathrm{E}-88^{\circ} \mathrm{E}$ and $18^{\circ} \mathrm{N}-28^{\circ} \mathrm{N}$ ). Results suggest that the model simulations with RUC, Noah and Noah-MP LSMs have better skill on the temperature, moisture and rainfall prediction than the experiment with TDS LSM.

\section{Summary and Conclusions}

A series of simulations at a $10 \mathrm{~km}$ spatial resolution using the WRF model was performed for five months starting from May to September during the year of 2010 to assess the skill of different LSMs in simulating ISM-2010 characteristics. This study also focuses on the better performance of multi-physical LSMs (i.e. Noah, RUC and NoahMP) over the simple LSM (TDS) in simulating 
ISM-2010. The model validation is carried out with the state-of-the-art reanalysis (ERAI), in situ (IMD) and satellite (TRMM)observations. Analysis revealed that the basic monsoon characteristics such as the monsoon trough, mid-tropospheric temperature, low level jet, moist instability and major precipitation zones are fairly reproduced by the WRF experiments with all LSMs with some regional discrepancies. The WRF model with selected LSMs are able to reproduce the broad ISM rainfall patterns including the orography-induced rainfall over the Himalayan region and the dry zone over the southern tip of India. The unrealistic precipitation over the equatorial western Indian Ocean is simulated by all LSMs based model simulations which is reflected from driving analysis (Raju et al. 2015a,b). Recently, Raju et al. (2017) demonstrated that the assimilation of temperature and water vapour profiles in the model could eliminate the unrealistic precipitation band over the western Indian Ocean. The WRF model with RUC and Noah-MP performed better for rainfall prediction over the monsoon core region. All LSM based model experiments are very consistent in predicting the spatial and temporal evolution of soil temperature and soil moisture during ISM-2010. However, RUC and Noah-MP based model simulations are in close agreement with the observed structures of soil temperature and moisture.

Detailed analysis suggests that the predictions of surface and upper-level temperature, as well as dew point temperature and water vapour mixing ratio are better in model simulations with Noah, Noah-MP, and RUC LSM than TDS LSM. Particularly, the errors over Tibetan and west Asia regions are substantially reduced with complex LSMs. Among all LSMs, the simulation with RUC is found to be the best in predicting surface temperature, whereas Noah and Noah-MP based model simulations are superior in middle to upper-level temperature predictions compared to ERAI. On the contrary, the surface water vapor prediction is much better with RUC and Noah-MP based simulations than with TDS LSM. In case of surface winds, TDS LSM based model experiment exhibit better skill than the other LSM based model 
experiments. The simulations with Noah, RUC and Noah-MP LSMs show the minimum error in thermodynamical fields over the Indian region. The WRF-TDS based model simulation significantly improved the ISM rainfall forecast over the north-east India. Overall, it is found that the monsoon-associated surface characteristics (i.e. $2 \mathrm{~m}$ temperature, winds and soil temperature and moisture) in the model are sensitive to different LSMs. Our analysis clearly suggests that the land-atmosphere interactions in the WRF model have discrepancies in simulating ISM-2010. Therefore, further improvements are essential in LSMs for ISM region. Our study is useful for future diagnosis of WRF model discrepancies related to LSMs in monsoon prediction studies. In the future, we will carry out longer period runs with different ensembles in order to establish the robustness of the results for the monsoon climate perspective.

\section{Acknowledgments}

Authors are grateful for the contribution of the anonymous reviewers and Editor whose constructive comments and valuable suggestions have substantially improved this article. Authors are thankful to IMD, ECMWF and TRMM for providing datasets used in this study. The second author is thankful to Space Applications Centre (SAC-ISRO) for logistic support. We also acknowledge Dr. Ravi Kumar Kunchala on the scientific discussions during the manuscript preparation.

\section{References}

Anthes, R.A, Kuo, Y.-H., Hsie, E.-Y., Low-Nam, S., and Bettge, T.W. (1989). Estimation of skill and uncertainty in regional numerical models. Q. J. R. Meteorol. Soc. 115, 763-806. 
Asharaf, S., Dobler, A., Ahrens, B. (2012). Soil moisture-precipitation feedback processes in the Indian summer monsoon season. J. Hydrometeor., 13:1461-74. http://dx.doi.org/10.1175/JHM-D-1206.1 .

Betts, A. K., Ball, J. H., Beljaars, A., Miller, M. J., Viterbo, P. A. (1996). The land surface-atmosphere interaction: A review based on observational and global modeling perspectives. J. Geophys. Res., 101(D3), 7209-7225, doi:10.1029/95JD02135.

Boos, W. R., Kuang, Z. M. (2013). Sensitivity of the South Asian monsoon to elevated and non-elevated heating. Sci. Rep., 3, 1192, doi:10.1038/srep01192.

Cai, X., Yang, Z. L., Xia, Y., Huang, M., Wei, H., Leung, L. R., Ek, M. B. (2014). Assessment of simulated water balance from Noah, Noah-MP, CLM, and VIC over CONUS using the NLDAS test bed, J. Geophys. Res. Atmos., 119, 13,751-13,770, doi:10.1002/2014JD022113.

Chen F., Dudhia, J. (2001). Coupling an Advanced Land Surface-Hydrology Model with the Penn StateNCAR MM5 Modeling System. Part I: Model Implementation and Sensitivity, Mon. Wea. Rev., 129, $\quad$ pp, 569-585, doi: http://dx.doi.org/10.1175/15200493(2001)129<0569:CAALSH>2.0.CO;2

Chen, S.H., Sun, W.Y. (2002). A one dimensional time-dependent cloud model. J. Meteorol. Soc. Jpn., 80, 99-118, doi: http://doi.org/10.2151/jmsj.80.99.

Clapp R. B., Hornberger, G. M. (1978). Empirical equations for some soil hydraulic properties, Water Resour. Res., 14(4), 601-604, doi:10.1029/WR014i004p00601.

Dickinson, R. E., Shaikh, M., Bryant, R., Graumlich, L. (1998). Interactive canopies for a climatemodel. J. Clim., 11(11), 2823-2836, doi:http://dx.doi.org/10.1175/1520-0442(1998)011<2823: ICFACM $>2.0 . C O ; 2$.

Dorman J., Sellers, P. (1989). A global climatology of albedo, roughness length, and stomatal resistance for atmospheric general circulation models as represented by the Simple Biosphere Model SIB. J. Appl. Meteorol., 28, pp. 833-855, doi: http://dx.doi.org/10.1175/1520-0450(1989)028<0833: AGCOAR $>2.0 . \mathrm{CO} ; 2$. 
Dudhia, J. (1989). Numerical study of convection observed during the winter monsoon experiment using a mesoscale two-dimensional model. J. Atmos. Sci., 46:3077-3107, doi: http://dx.doi.org/10.1175/1520-0469(1989)046<3077:NSOCOD>2.0.CO;2.

Dudhia, J., 1996: A multi-layer soil temperature model for MM5. Preprints, Sixth PSU/NCAR Mesoscale Model Users' Workshop, Boulder, CO, NCAR, 49-50.

Ek, M. B., Mitchell, K. E., Lin, Y., Rogers, E., Grunmann, P., Koren, V., Gayno, G., Tarpley, J. D. (2003). Implementation of Noah land surface model advances in the National Centers for Environmental Prediction operational mesoscale Eta model, J. Geophys. Res., 108, 8851, doi:10.1029/2002JD003296, D22.

Ferranti, L., Slingo, J. M., Palmer, T. N., Hoskins, B. J. (1999). The effect of land-surface feedbacks on the monsoon circulation. Q. J. R. Meteorol. Soc. 125: 1527-1550. doi:10.1002/qj.49712555704.

Giorgi, F., et al., (2001). Regional climate information-evaluation and projections. Chapter 10 of: Climate Change 2001: The Scientific Basis. Contribution of Working Group I to the Third Assessment Report of the Intergovernmental Panel on Climate Change (J.T. Houghton et al., eds), Cambridge University Press, Cambridge, United Kingdom and New York, NY, USA, (583-638).

Hariprasad, D., Venkata Srinivas, C., Venkata Bhaskar Rao, D., \& Anjaneyulu, Y. (2011). Simulation of Indian monsoon extreme rainfall events during the decadal period 2000-2009 using a high resolution mesoscale model. Advances in Geosciences 6 (A), 31-48.

Huffman, G.J., Adler, R.F., Bolvin, D.T., Gu, G., Nelkin, E.J, Bowman, K.P, Hong, Y., Stocker, E.F., Wolff, D.B. (2007). The TRMM multisatellite precipitation analysis (TMPA): quasi-global, multiyear, combined-sensor precipitation estimates at Fine scales. J. Hydrometeor., 8:38-55, doi: http://dx.doi.org/10.1175/JHM560.1

Janjic, Z. I. (1994). The step-mountain eta coordinate model: further developments of the convection, viscous sublayer and turbulence closure schemes. Mon. Wea. Rev., 122, 927-945, doi: http://dx.doi.org/10.1175/1520-0493(1994)122<0927:TSMECM>2.0.CO;2. 
Jiang, X. Y., Niu, G.Y., Yang, Z.L. (2009). Impacts of vegetation and groundwater dynamics on warm season precipitation over the Central United States. J. Geophys. Res., 114, D06109, doi:10.1029/2008JD010756.

Kar, S. C., Mali, P., Routray, A. (2014). Impact of Land Surface Processes on the South Asian Monsoon Simulations Using WRF Modeling System. Pure Appl. Geophys., (2014) 171: 2461. doi:10.1007/s00024-014-0834-7.

Koster, et al. (The GLACE Team), (2004). Regions of strong coupling between soil moisture and precipitation. Science, 305, 1138-1140, DOI: 10.1126/science.1100217.

Krishnan, R., Mujumdar, M., Vaidya, V., Ramesh, K.V., Satyan, V. (2003). The abnormal Indian summer monsoon of 2000. J. Clim., 16:1177-1194.

Levermann, A., Schewe, J., Petoukhov, V., Held, H. (2009). Basic mechanism for abrupt monsoon transitions. Proc. Natl. Acad. Sci. 106(49):20572-20577, doi: 10.1073/pnas.0901414106.

Liang, X. Z., Xu, M., Gao, W., Kunkel, K., Slusser, J., Dai, Y., Min, Q., Houser, P. R., Rodell, M., Schaaf, C.B. Gao, F. (2005). Development of land surface albedo parameterization based on Moderate Resolution Imaging Spectroradiometer (MODIS) data. J. Geophys. Res., 110, D11107, doi:10.1029/2004JD005579.

Liang, X.-Z., Xu, M., Yuan, X., Ling, T., Choi, H.I., Zhang, F.,Chen, L., Liu, S., Su, S., Qiao, F.,He, Y., Wang, J. X. L., Kunkel, K. E., Gao, W., Joseph, E., Morris, V., Yu, T.-W., Dudhia, J., Michalakes, J. (2012) Regional Climate-Weather Research and Forecasting Model (CWRF). Bull. Amer. Meteor. Soc., 93, (1363-1387), doi: 10.1175/BAMS-D-11-00180.

Loveland T. R., Merchant, J. W., Reed, B. C., Brown, J. F., Ohlen, D. O., Olson, P., Hutchinson, J. (1995). Seasonal Land Cover Regions of the United States. Ann. Assoc. Amer. Geogr., 85, pp. 339-355.

McCumber M. C. (1980). A Numerical Simulation of the Influence of Heat and Moisture Fluxes upon Mesoscale Circulations, Ph. D Thesis, University of Virginia, 255 pp.

Meehl, G. A. (1997). The South Asian monsoon and the tropospheric biennial oscillation, J. Clim., 10, 1921-1943, doi: http://dx.doi.org/10.1175/1520-0442(1997)010<1921:TSAMAT>2.0.CO;2. 
Miller D. A., White, R. A. (1998). A Conterminous United States multi-layer soil characteristics data set for regional climate and hydrology modeling. Earth Interactions, 2. doi: http://dx.doi.org/10.1175/1087-3562(1998)002<0001:ACUSMS>2.3.CO;2.

Mlawer E.J., Taubman S.J., Brown, P.D., Iacono, M.J., Clough, S.A. (1997). Radiative transfer for inhomogeneous atmospheres: RRTM, a validated correlated-k model for the longwave. J. Geophys. Res., 102(D14), 16663-16682, doi:10.1029/97JD00237.

Monin A.S, Obukhov, A.M. (1954). Basic laws of turbulent mixing in the surface layer of the atmosphere (in Russian). Contrib Geophys Inst Acad Sci USSR 151:163-187.

Mujumdar, M., Preethi, B., Sabin, T.P., Ashok, K., Saeed, S., Pai, D.S., Krishnan, R. (2012). The Asian summer monsoon response to the La Niña event of 2010. Met. Apps., 19: 216-225. doi:10.1002/met.1301.

Niu, G.-Y., Yang, Z.-L., Dickinson, R. E., Gulden, L. E. (2005). A simple TOPMODEL-based runoff parameterization (SIMTOP) for use in global climate models. J. Geophys. Res., 110, D21106, doi:10.1029/2005JD006111.

Niu, G.-Y., Yang, Z.-L., Mitchell, K.E., Chen, F., Ek, M.B., Barlage, M., Kumar, A., Manning, K., Niyogi, D., Rosero, E., Tewari, M., Xia, Y. (2011). The community Noah land surface model with multiparameterization options (Noah-MP): 1. Model description and evaluation with localscale measurements. J. Geophys. Res., 116, D12109, doi:10.1029/2010JD015139.

Noh, Y., Cheon, W.G., Hong, S-Y, Raasch, S. (2003). Improvement of the K-proile model for the planetary boundary layer based on large eddy simulation data. Bound.-Layer Meteor., 107:401427, doi:10.1023/A:1022146015946.

Pai D.S., and Sreejith, O.P. (2011). Global and Regional circulation anomalies: A Report (Editors: Ajit Tyagi, Mazumdar AB, Pai DS), IMD Met. Monograph No. Synoptic Meteorology No. 10/2011, IMD, 63-78.

Pan, H.-L., Mahrt, L. (1987). Interaction between soil hydrology and boundary layer development. Bound.-Layer Meteor., 38: 185-202, doi:10.1007/BF00121563.

Pielke, R. A. (2001). Influence of the spatial distribution of vegetation and soils on the prediction of cumulus Convective rainfall. Rev. Geophys., 39(2), 151-177, doi:10.1029/1999RG000072. 
Prasanna, V. (2014). Impact of monsoon rainfall on the total food grain yield over India, J. Earth Syst. Sci., 123(5), 1129-1145, doi:10.1007/s12040-014-0444-x.

Rajeevan, M., Bhate, J., Kale, J.D., Lal, B. (2006). High resolution daily gridded rainfall data for the Indian region: analysis of break and active monsoon spells. Curr. Sci., 91:293-306, ISSN 00113891.

Rajeevan, M., Rohini, P., Niranjan Kumar, K., Srinivasan, J., Unnikrishnan, C. K. (2013). A study of vertical cloud structure of the Indian summer monsoon using CloudSat data. Clim. Dyn., 40: 637. doi:10.1007/s00382-012-1374-4.

Raju, A., Parekh, A., Gnanaseelan, C. (2014). Evolution of vertical moist thermodynamic structure associated with the Indian summer monsoon in a regional climate model. Pure Appl. Geophys. 171:1499-1518 doi:10.1007/s00024-013-0697-3.

Raju, A., Parekh, A., Chowdary, J.S., Gnanaseelan, C. (2015a). Assessment of the Indian summer monsoon in the WRF regional climate model. Clim. Dyn., 44:3077-3100. doi:10.1007/s00382014-2295-1.

Raju, A., Parekh, A., Kumar, P., Gnanaseelan, C. (2015b). Evaluation of the impact of AIRS profiles on prediction of Indian summer monsoon using WRF variational data assimilation system. J. Geophys. Res. Atmos., 120, doi:10.1002/2014JD023024.

Raju, A., Parekh, A., Sreenivas, P., Chowdary, J.S., and Gnanaseelan, C., (2015c). Estimation of improvement in Indian summer monsoon circulation by assimilation of temperature pro les in WRF model. IEEE J Sel Top Appl Earth Obs Remote Sens. doi:10.1109/JSTARS.2015.2410338.

Raju, A., Parekh, A., Chowdary, J.S., Gnanaseelan, C. (2017). Reanalysis of the Indian summer monsoon: four dimensional data assimilation of AIRS retrievals in a regional data assimilation and modeling framework. Clim. Dyn., DOI 10.1007/s00382-017-3781-z

Rosero, E., Yang, Z.-L., Gulden, L. E., Niu, G.-Y., Gochis, D. J. (2009). Evaluating enhanced hydrological representations in Noah LSM over transition zones: Implications for model development. J. Hydrometeor., 10(3), 600-622, doi:10.1175/2009jhm1029.1. 
Rosero, E., Yang, Z.-L., Wagener, T., Gulden, L. E., Yatheendradas, S., Niu, G.-Y. (2010). Quantifying parameter sensitivity, interaction, and transferability in hydrologically enhanced versions of the Noah land surface model over transition zones during the warm season. J. Geophys. Res., 115, D03106, doi:10.1029/2009JD012035.

Saha, S. K., Halder, S., Rao, A.S., Goswami, B.N. (2012). Modulation of ISOs by land-atmosphere feedback and contribution to the interannual variability of Indian summer monsoon. J. Geophys. Res., 117, D13101, doi:10.1029/2011JD017291.

Sabin, T.P., Krishnan, R., Ghattas, J., Denvil, S., Dufresne, J.-F., Hourdin, F., Pascal, T (2013). High resolution simulation of the South Asian monsoon using a variable resolution global climate model. Clim. Dyn., 41,173-194, doi:10.1007/s00382-012-1658-8.

Shukla, J., and Mintz, Y. (1982). Influence of land-surface evapotranspiration on the Earth's climate, Science, 215, 1498-1501., doi: 10.1126/science.215.4539.1498.

Simmons, A., Uppala, S., Dee, D., Kobayashi, S. (2007). ERA-Interim: New ECMWF reanalysis products from 1989 on-wards. ECMWF Newsletter, No. 110, ECMWF, Reading, UK, pp 25-35.

Singh, A.P., Mohanty, U.C., Sinha, P., Mandal, M. (2007). Influence of different land surface processes on Indian Summer Monsoon circulation. Nat. Hazards. 42, 423-438. doi:10.1007/s11069-0069079-9.

Skamarock, W.C., Klemp, J., Dudhia, J., Gill, D.O., Barker, D.M., Wang, W., Powers, J.G. (2008). A description of the advanced research WRF version 2. NCAR technical note, NCAR/TN- 468 ? STR. Mesoscale and Microscale Meteorology Division, National Center for Atmospheric Research, Boulder, CO, USA.

Smirnova, T. G., J. M. Brown, Benjamin, S.G. (1997). Performance of Different Soil Model Configurations in Simulating Ground Surface Temperature and Surface Fluxes. Mon. Wea. Rev., 125, 1870-1884, doi: http://dx.doi.org/10.1175/1520-0493(1997)125<1870:PODSMC> 2.0.CO;2.

Smirnova, T. G., Brown, J.M., Benjamin, S.G., Kim, D. (2000). Parameterization of cold-season processes in the MAPS land-surface scheme. J. Geophys. Res., 105(D3), 4077-4086, doi:10.1029/1999JD901047. 
Smirnova, T.G., Brown, J.M., Benjamin, S.G., Kenyon, J.S. (2016). Modifications to the rapid update cycle land surface model (RUC LSM) available in the weather research and forecasting (WRF) model. Mon. Wea. Rev., 144:1851-1865.

Srinivas, C. V., Hari Prasad, D., Bhaskar Rao, D. V., Anjaneyulu, Y., Baskaran, R., Venkatraman, B., (2013). Simulation of the Indian summer monsoon regional climate using advanced research WRF model. Int. J. Climatol., 33: 1195-1210. doi:10.1002/joc.3505.

Srinivas, C.V., Bhaskar Rao, D.V., Hari Prasad. D., Hari Prasad, K.B.R.R., Baskaran, Y.R., Venkatraman, B. (2014). A study on the influence of the Land Surface Processes on the Southwest Monsoon simulations using a Regional Climate model. Pure Appl. Geophys., doi: 10.1007/s00024-014-0905-9.

Srinivas CV, Hari Prasad D, Bhaskar Rao DV, Baskaran R, Venkatraman B (2015). Simulation of the Indian summer monsoon onset-phase rainfall using a regional model. Ann. Geophys. 33:10971115. doi:10.5194/angeo-33-1097-2015.

Srinivasan, J., and Smith, G. L. (1996). Meridional migration of tropical convergence zones. J. Appl. Meteorol., 35, 1189-1202, doi: http://dx.doi.org/10.1175/1520-0450(1996)035<1189: MMOTCZ>2.0.CO;2.

Takata, K., Saito, K., Yasunari, T. (2009). Changes in the Asian monsoon climate during 1700-1850 induced by preindustrial cultivation. Proc. Natl. Acad. Sci. U. S. A., 106, 9586-9589.

Thiebaux, J., Rogers, E., Wang, W., Katz, B. (2003). A new high resolution blended real-time global sea surface temperature analysis. Bull. Amer. Meteor. Soc., 84:45-656, doi: http://dx.doi.org/10.1175/BAMS-84-5-645.

Thornton, P. E., Lamarque, J.F., Rosenbloom, N.A., Mahowald, N.M., (2007). Influence of carbonnitrogen cycle coupling on land model response to $\mathrm{CO} 2$ fertilization and climate variability, Global Biogeochem. Cycles, 21, GB4018, doi:10.1029/2006GB002868.

Unnikrishnan, C. K., Rajeevan, M., Vijayabhaskara Rao, S., Manoj Kumar. (2013). Development of a high resolution land surface dataset for the South Asian monsoon region. Curr. Sci., 1235-1246. 
Viterbo, P., Beljaars, A. C. (1995). An improved land surface parameterization scheme in the ECMWF model and its validation. J. Clim, 8(11), 2716-2748, doi: http://dx.doi.org/10.1175/15200442(1995)008<2716:AILSPS>2.0.CO;2.

Wang, Y., Leung, L.R., McGregor, J.L., Lee, D.K., Wang, W.C., Ding, Y., and Kimura, F. (2004). Regional climate modeling: progress, challenges, and prospects. J. Meteorol. Soc. Jpn., 82: (1599-1628).

Wang, B., Yang, H. (2008). Hydrological issues in lateral boundary conditions for regional climate modeling: Simulation of East Asian summer monsoon in 1998. Clim. Dyn., 31: 477. doi:10.1007/s00382-008-0385-7.

Webster, P. J. (1983). Mechanisms of monsoon low-frequency variability: Surface hydrological effects. J. Atmos. Sci., 40, 2110-2124, doi: http://dx.doi.org/10.1175/1520-0469(1983)040<2110: MOMLFV $>2.0 . \mathrm{CO} ; 2$.

Webster, P. J., Palmer, T., Yanai, M., Tomas, R., Magana, V., Shukla, J., Yasunari, A., (1998). Monsoons: Processes, predictability, and the prospects for prediction. J. Geophys. Res., 103(C7), 1445114510.

Xu, X., Lu, C., Shi, X., and Ding, Y. (2010). Large-scale topography of China: A factor for the seasonal progression of the Meiyu rainband? J. Geophys. Res., 115, D02110, doi:10.1029/2009JD012444.

Xu, M., Liang, X. Z., Samel, A., Gao, W. (2014). MODIS consistent vegetation parameter specifications and their impacts on regional climate simulations. J. Clim., 27(22), 8578-8596. doi: http://dx.doi.org/10.1175/JCLI-D-14-00082.1

Yanai, M. H., Li, C. F., and Song, Z. S., (1992). Seasonal Heating of the Tibetan Plateau and Its Effects on the Evolution of the Asian Summer Monsoon. J. Meteorol. Soc. Jpn., 70(1B), 319-351.

Yanai M., Wu, G. (2006). Effects of the Tibetan plateau. In: Wang B (ed) The Asian monsoon. Springer, Berlin.

Yang, Z.-L., Dickinson, R. E., Henderson-Sellers, A., Pitman, A. J., (1995). Preliminary study of spinup processes in land surface models with the first stage data of Project for Intercomparison of 
Land Surface Parameterization Schemes Phase 1(a). J. Geophys. Res., 100(D8), 16553-16578, doi:10.1029/95JD01076.

Yuan, X., Liang, X. Z. (2011). Evaluation of a Conjunctive Surface-Subsurface Process model (CSSP) over the contiguous United States at regional-local scales. J. Hydrometeor., 12(4), 579-599, doi: 10.1175/2010JHM1302.1. 